\title{
Author Correction: What models eat
}

\author{
Daniel Engber
}

Correction to: Nature Medicine https://doi.org/10.1038/s41591-018-0055-1, published online 6 June 2018.

In the version of this article originally published, there was an error in the sentence "That quest, which started in the 1980s, continues through until today: For a paper published online in 2017, a group of researchers based at Brazil's Federal University of Rio Grande do Sul tested Sprague Dawley rats on either a high-fat diet, a cafeteria diet or what they called a 'Western diet', formulated to match up more closely with eating patterns in developed nations (it had $42.5 \%$ of its calories from fat and added salt and carbohydrates)." Wistar rats were used in the experiment, not Sprague Dawley rats. Also, in ref. 7, the first author's last name was listed as Bortoloin. The correct spelling is Bortolin. The errors have been corrected in the HTML and PDF versions of this article.

\section{Author Correction: STAT3 labels a subpopulation of reactive astrocytes required for brain metastasis}

Neibla Priego, Lucía Zhu, Cátia Monteiro, Manon Mulders, David Wasilewski, Wendy Bindeman, Laura Doglio, Liliana Martínez, Elena Martínez-Saez, Santiago Ramón y Cajal, Diego Megías, Elena Hernández-Encinas, Carmen Blanco-Aparicio, Lola Martínez, Eduardo Zarzuela, Javier Muñoz, Coral Fustero-Torre, Elena Piñeiro-Yáñez, Aurelio Hernández-Laín, Luca Bertero (D), Valeria Poli (D), Melchor Sanchez-Martinez, Javier A. Menendez, Riccardo Soffietti, Joaquim Bosch-Barrera (D) and Manuel Valiente (D)

Correction to: Nature Medicine https://doi.org/10.1038/s41591-018-0044-4, published online 11 June 2018.

In the version of this article originally published, the names of three authors were incorrect. The authors were listed as "Coral FusteroTorres", "Elena Pineiro" and "Melchor Sánchez-Martínez". Their respective names are "Coral Fustero-Torre”, "Elena Piñeiro-Yáñez" and "Melchor Sanchez-Martinez". The errors have been corrected in the print, HTML and PDF versions of this article.

\section{Author Correction: Thymosin $\alpha 1$ represents a potential potent single-molecule-based therapy for cystic fibrosis}

Luigina Romani, Vasilis Oikonomou, Silvia Moretti, Rossana G Iannitti, Maria Cristina D'Adamo, Valeria R Villella, Marilena Pariano, Luigi Sforna, Monica Borghi, Marina M Bellet, Francesca Fallarino, Maria Teresa Pallotta, Giuseppe Servillo, Eleonora Ferrari, Paolo Puccetti, Guido Kroemer, Mauro Pessia, Luigi Maiuri, Allan L Goldstein and Enrico Garaci

Correction to: Nature Medicine https://doi.org/10.1038/nm.4305, published online 10 April 2017.

In the version of this article originally published, some labels in Fig. 1f are incorrect. The " $\beta$-actin" labels on the second and fourth rows of blots should instead be " $\beta$-tubulin". The error has been corrected in the HTML and PDF versions of this article. 